\title{
PEMANFAATAN TUMBUHAN OBAT OLEH SUKU DAYAK KANAYATN DI DESA MAMEK KECAMATAN MENYUKE KABUPATEN LANDAK
}

\author{
(Utilization of Medicinal Plants by Dayak Kanayatn In Mamek Village, Menyuke Sub-District \\ Landak District)
}

\author{
Richi Riadi, H.A Oramahi, Fathul Yusro \\ Fakultas Kehutanan Universitas Tanjungpura Pontianak. Jl. Daya Nasional Pontianak 78124 \\ Email: richiriadi123@gmail.com
}

\begin{abstract}
Mamek village of Menyuke district of Landak Regency is one of the villages with Dayak Kanatytn as its majority ethnic and they still use medicinal plants. The aims of this research were to catalogue the medicinal plants and its utilization pattern of Dayak Kanaytn in Mamek village. Data were collected by interviews the selected respondents through questionnaire. The purposive sampling method was carried out and as much as $20 \%$ of total households of Mamek village was selected. There were 40 species of medicinal plants belongs to 31 plants family were used by Dayak Kanatyn in Mamek village. Types of medicinal plants based on leaf parts (18 plants species or $45 \%$ ), decoction is the most common preparation method (32 species or $80 \%$ ), oral is the most administration method (72\%), home yard is the most plants sources location (17 species or 42,5\%), and cultivated is the most cultivation method (35 species or 87,5\%). The highest use value (UV) derived from sambung nyawa (Gymnathemum amygdalinum) (0.63). The highest informant consensus factor (ICF) with value 1 were obtained from diseases such as blood vomit, internal wound, swollen, sore, diarrhea, hepatitis, jaundice, measles, body odor, menstruation, urolitiasis, urinary tract infection, asthma, typhus, diabetic, mouthwash, digestion and palpitation. The highest fidelity level $(F L)$ is $100 \%$ and value derived from alang karue (Imperata Cylindrica), bawang merah (Allium cepa), bawang putih (Allium sativum), landep (Barleria prionitis), lengkuas (Alpinia galangal), bunga perujan (Ixora stricta roxb), ceri (Prunus avium), daun kesum (Polygonum minus), pepaya (Carica papaya), kedondong (Spondias dulcis forst), timun (Cucumis sativus), kelapa kuning (Cocos nucifera), mahkota dewa (Phaleria macrocarpa), pandan wangi (Pandanus amaryllifolius), puring (Codiaeum variegatum), lokop (Physalis peruviana) dengan nilai 100\%.
\end{abstract}

Keywords: Dayak Kanayatn, Medicinal Plants, Mamek Village

\section{PENDAHULUAN}

Kekayaan alam yang dimiliki oleh provinsi Kalimantan Barat khususnya jenis-jenis tumbuhan telah dimanfaatkan oleh masyarakat sejak zaman dahulu, terutama oleh suku Dayak yang merupakan suku Asli Kalimantan. Sekitar 1000 jenis tumbuhan telah teridentifikasi berada di Kalimantan Barat dan 300 jenis diantaranya telah digunakan dalam pengobatan tradisional (Wardani, 2008). Tumbuhan obat merupakan bagian yang tidak terpisahkan dalam kehidupan masyarakat khususnya suku dayak yang memang dikenal hidup dekat dengan alam, dimana dalam perawatan ataupun pengobatan suatu penyakit yang tergolong ringan maupun berat, dapat diatasi dengan ramuan yang terbuat dari berbagai macam tumbuhan. 
Suku Dayak yang ada di Kalimantan Barat terbagi dalam beberapa sub suku, salah satunya adalah suku Dayak Kanayatn, yang tersebar di beberapa Kabupaten seperti Landak, Mempawah, Kubu Raya, Bengkayang, serta sebagian kecil berada di Kabupaten Sanggau dan Ketapang (Alloy et al. 2008). Jenis-jenis tumbuhan obat oleh suku Dayak Kanayatn dibeberapa kabupaten telah terindentifikasi dan penggunaannya sangat beragam, seperti di desa Kayu Tanam Kecamatan Mandor Kabupaten Landak yang menggunakan 50 spesies (34 famili) tumbuhan obat (Efremila, 2015), dan di desa Sungai Enau Kecamatan Kuala Mandor B Kabupaten Kubu Raya yang menggunakan 29 species tumbuhan obat (Yusro et al. 2013). Dengan tersebarnya suku Dayak Kanayatn dibeberapa Kabupaten dan masih minimnya data mengenai tumbuhan obat yang digunakan oleh suku ini maka perlu dilakukan penelitian agar didapat data yang komprehensip terkait jenis-jenis tumbuhan obat yang digunakan oleh suku dayak Kanayatn di Kalimantan Barat.

Desa Mamek Kecamatan Menyuke Kabupaten Landak merupakan salah satu desa dengan mayoritas penduduknya merupakan suku Dayak Kanayatn dan sampai saat ini masih memanfaatkan tumbuhan sebagai tumbuhan obat dan tetap mempertahankan tradisi pengobatan tradisional sebagai salah satu kearifan lokal, namun sejauh ini tingkat pengetahuan masyarakat terkait pemanfaatan tumbuhan obat belum diketahui. Mengingat penelitian etnobotani tumbuhan yang berperan sebagai obat tradisional oleh Suku Dayak Kanayatn di Desa Mamek belum pernah dikaji, oleh sebab itu penelitian ini perlu dilakukan sebagai langkah awal untuk menganalisis jenis tumbuhan yang dimanfaatkan dan bagaimana cara pemanfaatannya.Tujuan dari penelitian ini adalah untuk mendata jenis-jenis tumbuhan obat, dan proses pengolahannya serta cara pengunaannya oleh masyarakat Suku Dayak Kanayatn Desa Mamek Kecamatan Menyuke Kabupaten Landak.

\section{METODE PENELITIAN}

Penelitian ini dilakukan di Desa Mamek Kecamatan Menyuke Kabupaten Landak (Gambar 1) selama \pm 3 minggu efektif di lapangan dan kemudian dilanjutkan dengan analisis data. Alat yang digunakan antara lain daftar pertanyaan atau kuisoner untuk responden, kamera, tally sheet, dan perekam suara (tape recorder). Pengumpulan data yang dilakukan dengan wawancara terhadap responden terpilih. Pemilihan responden dilakukan dengan secara Purposive Sampling dengan jumlah responden sebanyak $20 \%$ (Idrus, 2009) dari keseluruhan jumlah KK yang terdapat di desa Mamek (100 KK). Kriteria responden adalah masyarakat dari Suku Dayak Kanayatn yang minimal berusia 17 tahun dan berdomisili di Desa Mamek selama lima tahun. Jenis-jenis tumbuhan yang diperoleh dari hasil 
wawancara selanjutnya dilakukan indentifikasi dengan melakukan cek silang dengan berbagai buku/literatur tentang tumbuhan obat yang ada meliputi nama lokal dan latin, famili, habitus, bagian yang digunakan, cara pengolahan, cara penggunakan, dan khasiat (Nurdiana, 2014).

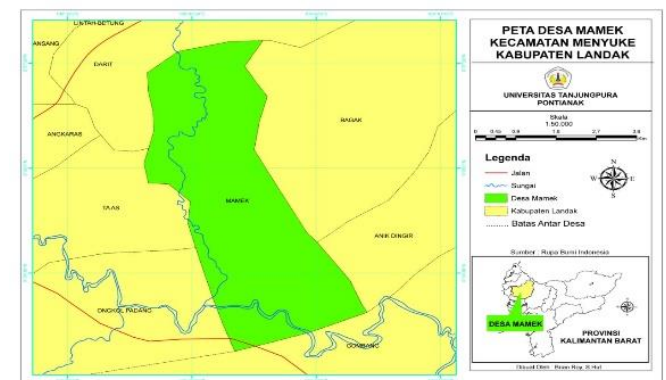

Gambar 1. Peta lokasi penelitian tumbuhan obat di desa Mamek Kecamatan Menyuke Kabupaten Landak (Map of research location of study of medicinal plants in Mamek village Menyuke District, Landak

\section{Analisis Data} Regency)

Analisis data dilakukan dalam bentuk tabulasi hasil dari wawancara kepada responden dan dilakukan analisis kuantitatif dan deskriptif. Adapun data tabulasi dikelola dengan cara mengklasifikasikan tumbuhan obat dengan mengidentifikasi jenis tumbuhan menggunakan buku panduan tumbuhan berkhasiat obat dan media internet. Pembuatan thally sheet bertujuan untuk merangkum identitas responden dan data tanaman seperti nama lokal, nama latin, family, cara pengolahan, bagian yang digunakan, dan khasiat tumbuhan obat. Analisis deskriptif bertujuan untuk memberikan gambaran serta penjelasan terhadap seluruh data yang terkumpul, dari data tersebut akan diperoleh hasil berupa bagian tumbuhan obat yang digunakan, cara pengolahan, serta pengunaan, dan jenis penyakit yang diobati akan dicatat dengan tally sheet. Kemudian analisis kuantitatif terkait dengan jenis-jenis dan pola pemanfaatannya akan dihitung dengan mengunakan rumus Use Value (UV), Informan Consencus Factor (ICF) dan Fidelity level (FL)

1. Use Value (UV)

Nilai penggunaan (UV) menunjukkan kepentingan relatif spesies tanaman yang dikenal secara lokal dan ditentukan jumlah laporan penggunaan yang dijelaskan oleh masing-masing informan untuk setiap spesies (Napagoda et al. 2014).

$\mathrm{UV}=\sum \mathrm{U} / \mathrm{n}$

Keterangan:

$\mathrm{UV}=$ Use Value $=$ Nilai Penggunaan Suatu Spesies Tumbuhan

$\mathrm{U}=$ Jumlah Informan yang Mengetahui/ Memanfaatkan Per Spesies

$\mathrm{n} \quad=$ Jumlah Total Responden

2. Informan consensus factor (ICF)

Dihitung untuk setiap kategori penyakit untuk mengidentifikasi kesepakatan masyarakat mengenai jenis tanaman yang digunakan untuk mengobati penyakit tertentu penyakit tertentu (Tariq et al. 2014).

$\mathrm{ICF}=($ Nur-Nt $) /($ Nur -1$)$

Keterangan:

$\mathrm{ICF}=$ Nilai Informan Consensus Factor 
Nur $=$ Jumlah Penggunaan Spesies Tumbuhan untuk Setiap Kategori Penyakit

$\mathrm{Nt}=$ Jumlah Taksa yang Digunakan/Kategori Tertentu oleh Semua Responden

\section{Fidelity level (FL)}

Fidelity level (FL) berguna untuk mengenali tanaman yang paling disukai yang digunakan untuk menyembuhkan penyakit tertentu oleh responden (Andriamparany et al. 2014).

$\mathrm{FL}(\%)=(\mathrm{Np} / \mathrm{N}) \times 100$

Keterangan:

$$
\begin{aligned}
& \mathrm{FL}=\text { Nilai Fidelity Level } \\
& \mathrm{Np}=\text { Jumlah Responden yang }
\end{aligned}
$$

Melaporkan Pemanfaatan Tanaman Obat/ Penyakit Tertentu

$\mathrm{N}$ = Jumlah Total Responden yang Menyebutkan Tanaman yang Sama untuk Setiap Jenis Penyakit

\section{HASIL DAN PEMBAHASAN}

\section{Jenis-jenis Tumbuhan Obat}

Berdasarkan hasil wawancara diperoleh 40 spesies tumbuhan obat dari 31 family yang di manfaatkan oleh suku Dayak Kanayatn di Desa Mamek. Hasil penelitian ini lebih banyak jika dibandingkan dengan hasil penelitian Yusro et al. (2013), dimana suku Dayak Kanayatn di desa Sungai Enau Kecamatan Kuala Mandor B Kabupaten Kuburaya hanya menggunakan 29 species tumbuhan obat. Hal ini mengindikasikan bahwa tumbuhan obat masih menjadi bagian dari pengobatan tradisional masyarakat dan hal ini didukung dengan keberadaan atau lokasi Desa Mamek yang jauh dari pusat kota Landak sehingga tumbuhan obat masih menjadi salah satu alternative utama dalam pengobatan suatu penyakit.

Pemanfaatan jenis-jenis tumbuhan obat berdasarkan jumlah pengguna (Use Value)

Pemanfaatan jenis-jenis tanaman dan pola pemanfaatan obat yang digunakan oleh masyarakat Desa Mamek berdasarkan hasil perhitungan Use value (UV) dari 100 jumlah responden terdapat 63 responden yang menggunakan sambung nyawa sebagai obat kolestrol, asam urat dan gula darah dengan nilai tertinggi yaitu 0.63 . Sedangkan hasil terendah terdapat pada jenis tumbuhan puring sebagai obat demam, mulas dan cacingan dengan jumlah pengguna 2 responden dari 100 responden dengan nilai 0.02 .

\section{Informant consensus factor (ICF)}

Analisis ICF digunakan untuk mengetahui tingkat homogenitas antara informasi yang diberikan oleh informan berbeda pada daerah penelitian untuk kategori penyakit tertentu (Trotter, 1986). Menurut Gazzaneo (2005), nilai ICF akan bernilai rendah (mendekati nol) jika informan tidak bertukar informasi tentang penggunaan tumbuhan tersebut dalam pengobatan tradisional. Nilai akan tinggi (mendekati satu) jika ada kriteria seleksi yang didefinisikan dengan baik di masyarakat dan atau jika informan saling bertukar informasi. Dalam hal ini dapat dikatakan bahwa nilai ICF merupakan nilai yang menunjukan keseragamaan informasi antar informan yang menjadi sampel dalam penelitian. Berdasarkan hasil perhitugan ICF, dari 43 jenis 
penyakit terdapat 24 jenis penyakit yang memiliki tingkat homogenitas atau keseragaman informasi yang tinggi (ICF = 1) yaitu: diare, maag, diabetes, bengkak, haid, menguatkan gigi, muntah darah, pendarahan, kerumut, tipes, luka dalam, sariawan, bau badan, amandel, asma, jantung bedebar, penyakit kuning, Tbc, pencernaan, batu ginjal, kecing batu, hepatitis, obat kumur, kantung kemih.

Tabel 2. Kategori Penyakit dan Informan Konsensus Faktor (Desesaes category and Informant Consensus Factor, ICF) (Disease Category and Informant Consensus Factor (ICF))

\begin{tabular}{|c|c|c|c|c|}
\hline No & Kategori Penyakit & Jumlah Penggunaan (Nr) & Jumlah Tanaman (Nt) & ICF \\
\hline 1 & Diare & 35 & 1 & 1,00 \\
\hline 2 & Maag & 35 & 1 & 1,00 \\
\hline 3 & Diabetes & 33 & 1 & 1,00 \\
\hline 4 & Bengkak & 30 & 1 & 1,00 \\
\hline 5 & Haid & 27 & 1 & 1,00 \\
\hline 6 & Menguatkan gigi & 23 & 1 & 1,00 \\
\hline 7 & Muntah darah & 22 & 1 & 1,00 \\
\hline 8 & Pendarahan & 22 & 1 & 1,00 \\
\hline 9 & Kerumut & 21 & 1 & 1,00 \\
\hline 10 & Tipes & 20 & 1 & 1,00 \\
\hline 11 & Luka dalam & 19 & 1 & 1,00 \\
\hline 12 & Sariawan & 18 & 1 & 1,00 \\
\hline 13 & Bau badan & 17 & 1 & 1,00 \\
\hline 14 & Amandel & 14 & 1 & 1,00 \\
\hline 15 & Asma & 13 & 1 & 1,00 \\
\hline 16 & Jantung bedebar & 13 & 1 & 1,00 \\
\hline 17 & Penyakit kuning & 12 & 1 & 1,00 \\
\hline 18 & Tbc & 12 & 1 & 1,00 \\
\hline 19 & Pencernaan & 10 & 1 & 1,00 \\
\hline 20 & Batu ginjal & 10 & 1 & 1,00 \\
\hline 21 & Kecing batu & 10 & 1 & 1,00 \\
\hline 22 & Hepatitis & 10 & 1 & 1,00 \\
\hline 23 & Obat kumur & 10 & 1 & 1,00 \\
\hline 24 & Kantung kemih & 8 & 1 & 1,00 \\
\hline 25 & Kolestrol & 55 & 2 & 0,98 \\
\hline 26 & Rematik & 44 & 2 & 0,98 \\
\hline 27 & Darah tinggi & 39 & 2 & 0,97 \\
\hline 28 & Kencing manis & 35 & 2 & 0,97 \\
\hline 29 & Keputihan & 30 & 2 & 0,97 \\
\hline 30 & Bau mulut & 28 & 2 & 0,96 \\
\hline 31 & Sakit kepala & 27 & 2 & 0,96 \\
\hline 32 & Sakit tengorokan & 25 & 2 & 0,96 \\
\hline 33 & Sakit gigi & 25 & 2 & 0,96 \\
\hline 34 & Sakit perut & 23 & 2 & 0,95 \\
\hline 35 & Demam & 38 & 3 & 0,95 \\
\hline 36 & Masuk angin & 37 & 3 & 0,94 \\
\hline 37 & Asam urat & 53 & 4 & 0,94 \\
\hline 38 & Malaria & 31 & 3 & 0,93 \\
\hline 39 & Sakit sendi & 15 & 2 & 0,93 \\
\hline 40 & Cacingan & 19 & 3 & 0,89 \\
\hline 41 & Penyakit kulit & 28 & 5 & 0,85 \\
\hline 42 & Batuk & 30 & 6 & 0,83 \\
\hline 43 & Panas dalam & 15 & 4 & 0,79 \\
\hline
\end{tabular}




\section{Fidelity Level (FL)}

Nilai FL digunakan untuk mengetahui jenis tumbuhan yang paling disukai untuk kegunaan tertentu, sehingga tumbuhan yang banyak dimanfaatkan masyarakat lokal untuk kegunaan tertentu memiliki nilai FL lebih tinggi dibanding tumbuhan lain yang kurang populer (Alexiades, 1996). Khan (2014) menambahkan bahwa nilai FL menunjukkan persentase informan dalam memanfaatkan suatu jenis tumbuhan untuk tujuan utama yang sama. Berdasarkan hasil perhitungan Fidelity Level (FL) dari 40 jenis-jenis tumbuhan yang digunakan oleh Suku Dayak Kanayatn diperoleh hasil tertinggi dengan rata-rata nilai $100 \%$ sebanyak 16 jenis tanaman yaitu alang karue untuk penyakit muntah darah, bawang merah untuk masuk angin, bawang putih, landep dan lengkuas untuk penyakit kulit, lokop untuk sakit tengorokan, bunga perujan untuk luka dalam, ceri untuk asam urat, daun kesum untuk pencernaan, pepaya untuk malaria, kedondong dan timun untuk darah tinggi, kelapa kuning untuk kerumut, mahkota dewa untuk hepatitis, pandan wangi dan puring untuk sakit gigi. Sedangkan hasil terendah terdapat pada mengkudu dengan nilai $2,63 \%$. Dari hasil perhitungan fidelity level hasil tertinggi untuk penyakit dalam adalah muntah darah, kencing manis, luka dalam, pencernaan, darah tinggi, hepatitis, sakit gigi, demam, mulas dan cacingan. Untuk penyakit luar adalah penyakit kulit, luka luar, kerumut.

Tabel 3. Nilai Fidelity Level (FL) Jenis-Jenis Tumbuhan yang Digunakan oleh Suku Dayak Kanayatn (Fidelity level values (FL) of the medicinal plants species used by Kanayatn Dayak)

\begin{tabular}{|c|c|c|}
\hline No & $\begin{array}{l}\text { Kategori } \\
\text { Penyakit }\end{array}$ & Jenis tanaman \\
\hline 1 & Muntah darah & Alang karue $(100 \%)$ \\
\hline 2 & Masuk angin & Bawang merah (100\%), jahe $(66,67 \%)$, kunyit putih $(28 \%)$ \\
\hline 3 & Penyakit kulit & $\begin{array}{l}\text { Bawang putih }(100 \%) \text {, landep }(100 \%) \text {, lengkuas }(100 \%) \text {, pinang }(8 \%) \text {, sabihloto } \\
(8 \%)\end{array}$ \\
\hline 4 & Sakit sendi & Belimbing $(16,67 \%)$, cengkodok $(17,46 \%)$ \\
\hline 5 & Sakit tengorokan & Belimbing $(62,50 \%)$, lokop $(100 \%)$ \\
\hline 6 & Kencing manis & Belimbing $(20,83 \%)$, lidah buaya $(83,33 \%)$ \\
\hline 7 & Luka dalam & Bunga perujan $(100 \%)$ \\
\hline 8 & Bengkak & Cengkodok $(48 \%)$ \\
\hline 9 & Pendarahan & Cengkodok $(35 \%)$ \\
\hline 10 & Asam urat & $\begin{array}{l}\text { Ceri }(100 \%) \text {, lada }(13,04 \%) \text {, sambung nyawa }(44,44 \%) \\
\text { terung pipit }(25 \%)\end{array}$ \\
\hline 11 & Rematik & Cocor bebek $(65,79 \%)$, kayu manis $(82,61 \%)$ \\
\hline 12 & Demam & Cocor bebek $(34,21 \%)$, mengkudu $(44,74 \%)$, puring $(72,23 \%)$ \\
\hline 13 & Pencernaan & Daun kesum (100\%) \\
\hline 14 & Sariawan & Daun sirih $(46 \%)$ \\
\hline 15 & Bau mulut & Daun sirih $(20,51 \%)$, kemangi $(30,30 \%)$ \\
\hline 16 & Keputihan & Daun sirih $(9,09 \%)$, kumis kucing $(28,00 \%)$ \\
\hline 17 & Kolestrol & Jahe $(33,33 \%)$, sambung nyawa $(55,56 \%)$ \\
\hline 18 & Diare & Jambu biji $(51 \%)$ \\
\hline 19 & Batuk & $\begin{array}{l}\text { Jeruk nipis }(69,23 \%) \text {, kayu manis }(17,39 \%) \text {, meniran }(20,00 \%) \text { Mengkudu } \\
(2,63 \%) \text {, rumput setan }(6,67 \%) \text {, sabihloto }(6,67)\end{array}$ \\
\hline
\end{tabular}




\begin{tabular}{|c|c|c|}
\hline No & $\begin{array}{l}\text { Kategori } \\
\text { Penyakit }\end{array}$ & Jenis tanaman \\
\hline 20 & Panas dalam & $\begin{array}{l}\text { Jeruk nipis }(30,77 \%) \text {, kemangi }(3,03 \%) \text {, kunyit putih }(12 \%) \text {, terung pipit } \\
(10,00 \%)\end{array}$ \\
\hline 21 & Batu ginjal & Kacang panjang $(48 \%)$ \\
\hline 22 & Malaria & Kacang panjang $(52,38 \%)$, mengkudu $(26,32 \%)$, pepaya $(100 \%)$ \\
\hline 23 & Darah tinggi & Kedondong $(100 \%)$, timun $(100 \%)$ \\
\hline 24 & Kerumut & Kelapa kuning (100\%) \\
\hline 25 & Bau badan & Kemangi $(26 \%)$ \\
\hline 26 & Haid & Kemangi (41\%) \\
\hline 27 & Kecing batu & Kumis kucing $(40 \%)$ \\
\hline 28 & Kantung kemih & Kumis kucing $(32 \%)$ \\
\hline 29 & Sakit perut & Kunyit putih $(60 \%)$, Serai $(44,44 \%)$ \\
\hline 30 & Sakit kepala & Lada $(30,43 \%)$, sabihloto $(44,44 \%)$ \\
\hline 31 & Asma & Lada $(57 \%)$ \\
\hline 32 & Cacingan & Lidah buaya $(16,67 \%)$, mengkudu $(26,32 \%)$, puring $(27,27 \%)$ \\
\hline 33 & Hepatitis & Mahkota dewa $(100 \%)$ \\
\hline 34 & Penyakit kuning & Meniran $(80 \%)$ \\
\hline 35 & Sakit gigi & Pandan wangi (100\%), Puring $(100 \%)$ \\
\hline 36 & Menguatkan gigi & Pinang $(92 \%)$ \\
\hline 37 & $\mathrm{Tbc}$ & Rinyuang $(26 \%)$ \\
\hline 38 & Maag & Rinyuang (74\%) \\
\hline 39 & Amandel & Rumput setan $(93 \%)$ \\
\hline 40 & Tipes & Sabihloto $(44 \%)$ \\
\hline 41 & Diabetes & Diabetes $(49 \%)$ \\
\hline 42 & Obat kumur & Serai $(56 \%)$ \\
\hline 43 & Jantung bedebar & Terung pipit $(65 \%)$ \\
\hline
\end{tabular}

\section{Pemanfaatan Tumbuhan Obat} Berdasarkan Family

Jenis tumbuhan obat yang paling banyak digunakan masyarakat Desa Mamek Kecamatan Menyuke adalah berjumlah 13 family yaitu berasal dari family Zingiberaceae sebanyak 3 spesies, dan Rubiaceae, Piperaceae, Fabaceae, Arecaceae, Liliaceae masing-masing 2 spesies, sedangkan family lainnya hanya 1 spesies saja. Menurut (Etikawati et al. 2013) bahwa tumbuhan dari suku Zingiberaceae memiliki senyawa aktif yang berpotensi sebagai obat, seperti zingeron, minyak atsiri, resin, alkaloid dan flavonoid. Tumbuhan dari suku ini banyak dimanfaatkan sebagai rempah-rempah dan bahan obat. Dari 3 spesies tersebut semuanya berbeda cara pemanfaatannya maupun kegunaannya.

\section{Pemanfaatan}

Tumbuhan

\section{Berdasarkan Bagian yang Digunakan}

Tumbuhan obat yang dimanfaatkan masyarakat dalam pemanfaatan tumbuhan sebagai obat dan bagianbagian tanaman yang biasa digunakan seperti bagian akar, batang, buah, daun, biji, bunga, rimpang, umbi, dan lainnya. Berdasarkan hasil penelitian dilapangan, 40 bagian tumbuhan yang paling banyak digunakan masyarakat sebagai bahan baku obat adalah pada bagian daun sebanyak 18 spesies dengan persentase sebesar $45 \%$ sedangkan yang paling sedikit adalah bagian bunga dan akar dengan persentase masing-masing sebesar 2,5\%. Menurut penelitian Maryadi et al. (2012) bahwa bagian 
tumbuhan yang paling banyak dimanfaatkan masyarakat adalah bagian daun yaitu sebesar 50\%, karena lebih mudah ditemukan/diperoleh kapan saja masyarakat membutuhkannya.

\section{Pemanfaatan Tumbuhan Obat Berdasarkan Cara Pengolahan}

Berdasarkan cara pengolahan tumbuhan obat, umumnya dilakukan dengan cara yang cukup sederhana. Dalam cara pengolahannya tumbuhan obat dimanfaatkan sebagian besar masyarakat masih menggunakan cara tradiosional, yaitu secara sederhana seperti dengan direbus, ditumbuk, maupun secara langsung dipergunakan. Berdasarkan penelitian dilapangan dari ketiga cara tersebut ternyata cara pengolahan tumbuhan yang paling banyak digunakan oleh masyarakat Desa Mamek adalah dengan cara direbus yaitu sebanyak 32 spesies (80\%).

\section{Pemanfaatan Tumbuhan Obat Berdasarkan Cara Penggunaan}

Masyarakat di Desa Mamek Kecamatan Menyuke Kabupaten Landak mengenal beberapa cara pengolahan tumbuhan obat, seperti direbus, ditumbuk, dan langsung dimakan. Berdasarkan penggunaannya, lebih banyak masyarakat menggunakan tumbuhan obat dengan cara diminum dengan persentase sebesar 72,5\%, dengan harapan obat tersebut dapat langsung masuk kedalam tubuh dan mengobati penyakit yang diderita, kemudian dengan cara ditempel sebesar $15 \%$, dimakan sebesar $10 \%$ dan yang paling sedikit yaitu dengan cara digosok dengan persetase sebesar 2,5\%. Rahmawati et al. (2012) penggunaan dengan cara diminum biasanya untuk pengobatan organ tubuh bagian dalam, sedangkan dua cara lainnya untuk pengobatan tubuh bagian luar, semua jenis tanaman obat memang mengandung senyawa kimia alami, yang memiliki efek farmakologis dan aktivitas penting sampai berpotensi sebagai agen anti penyakit degeneratif.

\section{Pemanfaatan Tumbuhan Obat \\ Berdasarkan Cara Memperoleh}

Berdasarkan cara memperoleh tumbuhan obat oleh masyarakat terdiri dari dihutan, dipasar, dipekarangan rumah, dikebun dan lain-lain. Tumbuhan obat yang paling banyak diperoleh di Desa Mamek yaitu di pekarangan rumah sebanyak 17 spesies dengan persentase sebesar $42,50 \%$, dan yang paling sedikit diperoleh yaitu dipasar sebanyak 2 spesies dengan persentase sebesar 5\%. Berbeda dengan penelitian Rahman, (2019) tumbuhan obat yang dimanfaatkan oleh oleh masyarakat berasal dari hutan tembawang.

$\begin{array}{ll}\text { Pemanfaatan } & \begin{array}{l}\text { Tumbuhan } \\ \text { Obat } \\ \text { Berdasarkan }\end{array} \\ \text { Menggobati Penyakit } & \end{array}$

Berdasarkan

manfaatnya pengobatan dengan menggunakan tumbuhan obat dapat diklasifikasikan menjadi dua macam yaitu penyakit luar dan penyakit dalam. Dari hasil penelitian ternyata masyarakat setempat dalam mengolah tumbuhan obat ini lebih banyak untuk penyakit dalam yaitu sebanyak 35 spesies $(87,5 \%)$, 
sedangkan untuk menggobati penyakit luar lebih sedikit yaitu 5 spesies $(12,5 \%)$. Keterbatasan sarana prasarana dan ekonomi menyebabkan pengobatan tradisional menjadi sebuah pilihan bagi masyarakat untuk pertolongan pertama, sering juga menjadi alternatif terakhir apabila pengobatan dengan cara modern tidak memberikan hasil (Erliyanti et al. 2010).

\section{Pemanfaatan Tumbuhan Obat Berdasarkan Pembudidayaan}

Berdasarkan penelitian dilapangan masyarakat Desa Mamek masih banyak yang membudidayakan tumbuhan obat tersebut dibandingkan dengan mendapatkannya secara liar dihutan, berdasarkan hasil penelitian dilapangan masyarakat Desa Mamek lebih banyak membudidayakan tumbuhan obat dengan persentase sebesar $65 \%$ dari pada mencari tumbuhan obat yang tumbuh dihutan secara liar dengan persentase sebesar 35\%. Berbeda dengan Hidayat (2008) yang menyatakan bahwa bahan baku yang digunakan sebagai tumbuhan obat di Indonesia sampai saat ini sebagian besar diperoleh dari tumbuhan liar, bukan tumbuhan hasil budidaya, dan pemanenan langsung tumbuhan liar yang melampaui batas kemampuan regenerasinya di alam nampaknya merupakan suatu faktor penting yang mengancam kelestarian tumbuhan obat.

\section{KESIMPULAN DAN SARAN}

Tumbuhan obat yang dimanfaatkan oleh suku dayak Kanayatn di Desa Mamek sebanyak 40 spesies (31 family). Penggunaan tumbuhan obat tertinggi adalah bagian daun 18 spesies (45\%), dengan cara direbus 32 spesies (80\%), dengan cara penggunan yaitu diminum $(72,5 \%)$. Untuk pengobatan penyakit dalam terdapat 35 spesies $(87,5 \%)$ yang digunakan, diperoleh di pekarangan rumah 17 spesies $(42,50 \%)$, dan diperoleh dengan cara budidaya sebesar 35 spesies (87,5\%). Use Value (UV) tertinggi adalah dari jenis tumbuhan sambung nyawa dengan nilai 0.63. Informant Consensus Factor (ICF) tertinggi terdapat pada jenis-jenis penyakit muntah darah, luka dalam, bengkak, sariawan, diare, batu ginjal, kerumut, bau badan, haid, kencing batu, kantung kemih, asma, hepatitis, penyakit kuning, pendarahan, menguat gigi, tbc, maag, amandel, tipes, diabetes, obat kumur, pencernaan, jantung bedebar dengan rata-rata nilai 1.00. Fidelity Level (FL) tertinggi terdapat pada tanaman alang karue, bawang merah, bawang putih, landep, lengkuas, bunga perujan, ceri, daun kesum, pepaya, kedondong, timun, kelapa kuning, mahkota dewa, pandan wangi, puring, lokop, dengan nilai 100\%. Dari hasil penelitian ini maka perlu adanya penelitian lebih lanjut untuk mengetahui berbagai komponen/senyawa bioaktif dan bioaktivitasnya sebagai bahan baku obat-obatan.

\section{DAFTAR PUSTAKA}

Alexiades, M. N. dan J. W. Sheldon. 1996. Selected Guidelines for Ethnobotanical Research: A Field Manual. New York: New York Botanical Garden. 99-133. 
A.Tariq, S. Mussarat, M. Adnan, N. M. AbdElsalam, R. Ullah, and A.L.Khan. 2014 Ethnoveterinary Study Of Medicinal Plantsin A Tribal Society Of Sulaiman Range. The Scientific World Journal vol 1 ArticleID127526,10pages.

Wardani, M, 2008. Keragaman Tumbuhan Berguna Di Cagar Alam Mandor, Kalimantan Barat. Jurnal Penelitian Hutan Dan Konservasi Alam5 (3) : 251-266.

Handayani, A. 2015. Pemanfaatan Tumbuhan Berkhasiat Obat Oleh Masyarakat Sekitar Cagar Alam Gunung Simpang, Jawa Barat. Prosiding Seminar Nasional Biodiversitas, 1(6) : 1425-1432.

Hidayat, Syamsul. 2008. Struktur, Komposisi, Dan Status Tumbuhan Obat Di Kawasan Hutan Tanam Alas Purwo. Jurnal Biologi 12 (1) : 9-13.

Alloy S, Albertus, Yovinus, Istiyani CP. 2008. Peta Keberagaman Subsuku Dayak Di Kalimatan Barat. Institut Dayakologi. Pontianak.

Fadilah, Lovandi, I, Linda, R. 2015. Pemanfaatan Tumbuhan Dalam Pengobatan Tradisional Masyarakat Suku Dayak Kanayatn Di Desa Ambawang Kecamatan Kubu Kabupaten Kubu Raya.Jurnal Protobiont 4 (3) : 49-59.

Gazzaneo, L. R. S., R. F. P. de Lucena, dan U. P. de Albuquerque. 2005. Knowledge and Use of Medicinal Plants by Local Specialists in an Region of Atlantic Forest in the State of Pernambuco (Northeastern Brazil). Journal Of
Ethnobiology and Ethnomedicine. Brazil: Universitas Federal Rural de Pernambuco. I:9.

Hidayat D, Hardiansyah G. 2012. Studi Keanekaragaman Jenis Tumbuhan Obat Di Kawasan IUPHHK PT. Sari Bumi Kusuma Camp Tontang Kabupaten Sintang. Vokasi 8 (2) : 61-68.

Idrus, M. 2009. Metode Penelitian Ilmu Sosial. Erlangga. Yogyakarta.

J. N. Andriamparany, K. Brinkmann, V. Jeannoda, and A. Buerkert. 2014. Effects of socio-economic household characteristics on traditional knowledge and usage of wild yams and medicinal plants in the Mahafaly region of southwestern Madagascar," Journal of Ethnobiology and Ethnomedicine $10(1): 82$.

Efrimila, Wardenaar, E, Sisillia L. 2015. Studi Etnobotani Tumbuhan Obat Oleh Etnis Suku Dayak Di Desa Kayu Tanam Kecamatan Mandor Kabupaten Landak. Jurnal Hutan Lestari 3 (2) : 234-246.

Khan, I., N. M. Abdelsalam, H. Fouad, A. Tariq, R. Ullah, dan M. Adnan. 2014. Application of Ethnobotanical Indices on the Use of Traditional Medicines Against Common Diseases. Evidencebased Complementary and Alternative Medicine. 1-22.

M. Napagoda, J. Gerstmeier, S. Weselyetal. 2014. Inhibition Of 5 Lipoxygenase As AntiInflammatory Mode Of Action Of Plectranthus Zeylanicus Benth And Chemical Characterization Of Ingredients By A Mass Spectrometric Approach. Journal 
of Ethnopharmacology 151 (2) : $800-809$.

Nurdiana, N. 2014. Teknik Sampling Snowball Dalam Penelitian Lapangan. Comtech5 (2) : 11101118.

Rahman, K, Wardenaar, E, Mariani, Y. 2019. Identifikasi Jenis Dan Pemanfaatan Tumbuhan Obat Di Hutan Tembawang Oleh Masyarakat Kelurahan Beringin Kecamatan Kapuas Kabupaten Sanggau. Jurnal Hutan Lestari Vol. 7 (1) : $44-55$

Rahmawati, U. Suryani, E. Mukhlason, A. (2012). Pengembangan
Repository Pengetahuan Berbasis Ontologi untuk Tanaman Obat Indonesia. Jurnal Teknik POMITS $1(1): 1$ - 6 .

Trotter, R, T, dan Logan, M. H. 1986. Plants in Indigenous Medicine and Diet: Biobehavioral Approaches. New York: Bedford Hill. 91-112.

Yusro, F, Diba, F, Mariani, Y, Ohtani, K. 2013. Pemanfaatan Tumbuhan Berkhasiat Obat Oleh Suku Dayak Kanayatn Di Desa Sungai Enau Kabupaten Kubu Raya. Indonesia Journal of Forestry 2 (1) : 30-34. 